\title{
Statins, bone biology and revision arthroplasty: review of clinical and experimental evidence
}

\author{
Antony K. Sorial (D), Sami A. Anjum, Michael J. Cook, Tim N. Board* \\ and Terence W. O'Neill*
}

\begin{abstract}
Osteoarthritis is a painful, disabling condition which is increasing in prevalence as a result of an ageing population. With no recognized disease-limiting therapeutics, arthroplasty of the hip and knee is the most common and effective treatment for lower limb osteoarthritis, however lower limb arthroplasty has a finite life-span and a proportion of patients will require revision arthroplasty. With increasing life expectancy and an increasing proportion of younger (<65years) patients undergoing arthroplasty, the demand for revision arthroplasty after implant failure is also set to increase.

Statins are cholesterol-modulating drugs widely used for cardiovascular risk reduction which have been noted to have pleiotropic effects including potentially influencing arthroplasty survival. In vitro studies have demonstrated pleiotropic effects in human bone cells, including enhancement of osteoblastogenesis following simvastatin exposure, and in vivo studies have demonstrated that intraperitoneal simvastatin can increase peri-implant bone growth in rats following titanium tibial implant insertion. There is evidence that statins may also influence osseointegration, enhancing bone growth at the bone-implant interface, subsequently improving the functional survival of implants. Data from the Danish Hip Arthroplasty Registry and the Clinical Practice Research Datalink in the UK suggest a reduction in the risk of lower limb revision arthroplasty in statin ever-users versus never-users, and a time-dependent effect of statins in reducing the risk of revision. In this article we review the clinical and experimental evidence linking statins and risk of revision arthroplasty.
\end{abstract}

Keywords: arthroplasty, hip, knee, loosening, osseointegration, osteolysis, revision, statin

Received: 10 December 2019; revised manuscript accepted: 14 September 2020.

\section{Introduction}

Osteoarthritis $(\mathrm{OA})$ is characterized by articular cartilage degeneration, pain and eventual disability. It is estimated that symptomatic OA affects one in eight men and women in the USA (27-31 million). ${ }^{1}$ Disability secondary to OA continues to rise, increasing by $16 \%$ between 1990 and $2010,{ }^{2}$ and the UK National Health Service continues to spend over $£ 900$ million annually directly treating the disease. ${ }^{3}$

Arthroplasty is an effective treatment for endstage OA which has not responded to conservative measures including analgesia and physiotherapy. ${ }^{4}$
Two of the most common interventions undertaken are primary total hip arthroplasty (THA) and primary total knee arthroplasty (TKA). According to the National Joint Registry (NJR) 91,698 primary THA and 102,177 primary TKA were undertaken in England, Wales and Northern Ireland in 2017, with greater than $90 \%$ of these being for the treatment of primary OA. ${ }^{5}$

A proportion of patients require revision of their primary surgery with the main indications for revision being (rate of revision/1000 patientyears) aseptic loosening (1.25 THA, 1.25 TKA), pain (0.84 THA, 0.85 TKA), dislocation (0.87
Ther Adv Musculoskel Dis

2020, Vol. 12: 1-9

DOI: $10.1177 /$

1759720X20966229

(c) The Author(s), 2020 Article reuse guidelines: sagepub.com/journalspermissions
Correspondence to: Antony K. Sorial

Newcastle University, Biosciences Institute, International Centre for Life, Newcastle upon Tyne, NE1 3BZ, UK tony.sorialancl.ac.uk

Sami A. Anjum Newcastle University, Newcastle upon Tyne, UK

Michael J. Cook

Centre for Epidemiology versus Arthritis, University of Manchester, Manchester, UK

Tim N. Board

The Centre for Hip Surgery, Wrightington, Wigan and Leigh NHS Foundation Trust, Wigan, UK

Terence W. O'Neill Centre for Epidemiology versus Arthritis, University of Manchester Manchester, UK, and NIHR Manchester Biomedical Research Centre, Manchester University NHS Foundation Trust, Manchester Academic Health Science Centre, UK

*Terence W. O'Neill and Tim N. Board contributed to this work equally. 
THA), adverse reaction to particulate debris (0.86 THA), infection (0.72 THA,), instability (0.69 TKA), malalignment (0.38 TKA) and periprosthetic fracture (0.69 THA, 0.16 TKA). ${ }^{5}$ Revision risk increases each year following primary arthroplasty and despite modern surgical advances and improvement in implant materials, the overall revision risk has remained relatively static for the last 5 years. ${ }^{5}$ Comparing 2010 and 2017 NJR data, the 5-year risk of revision was $2.5 \%$ and $2.34 \%$ for hips, and $2.7 \%$ and $2.65 \%$ for knees. ${ }^{5,6}$ When compared with primary arthroplasty, revision surgery is recognized to be more complex and is associated with increased risk of dislocation, venous thromboembolism, infection and mortality. ${ }^{7}$ Furthermore, functional improvement after revision surgery may be less than that from the primary procedure. ${ }^{8}$ In addition to being more burdensome at the patient level with a higher risk of failure, ${ }^{9}$ revision surgery impacts on a societal level with greater financial implications arising from increased length of hospital stay, operative time and complexity. ${ }^{7,10,11}$

With an ageing population, increasing life expectancy and rising obesity rates, the number of people requiring primary arthroplasty of the hip and knee is set to increase substantially.

Efforts to reduce the risk of revision have focused on intra-operative factors including reducing contamination at surgery, optimum placement of the prostheses and development of new implants. There is developing evidence from animal studies however, that 3-hydroxy-3-methylglutarylcoenzyme A (HMG-CoA) reductase inhibitors, commonly known as statins, may influence implant survival following arthroplasty.

This review was tailored to include all English language, peer-reviewed publications available via structured searches of Embase (1974-2019) and Ovid Medline (1946-2019) relating to statins, arthroplasty, revision and the identified mechanisms underlying this phenomenon including osteolysis, loosening, osseointegration and wear debris response. The reference list of each publication identified from searches was also reviewed for relevant articles. Epidemiological, clinical and laboratory studies were included.

\section{What are statins?}

Statins are cholesterol-modulating drugs that act upon the mevalonate pathway by inhibition of
HMG-CoA reductase. ${ }^{12}$ Reduction of cholesterol by statins has been shown consistently to improve survival in clinical trials by reducing fatal coronary events. ${ }^{13,14}$ The annual number of prescriptions of lipid-lowering drugs in England has increased significantly from 295,000 in 1981 to over 50 million in 2011.15 Derivatives of mevalonate are required in the post-translational modification of the triphosphate-binding proteins (GTPases) responsible for the regulation of osteoblastogenesis and osteoclastogenesis. ${ }^{16}$

\section{Statins and osseointegration of prosthetic implants and bone}

Osseointegration is necessary for implant stability and is a result of direct bone-to-implant contact. ${ }^{17}$ It is defined as the direct structural and functional connection between bone and implant such that there is no relative movement between the two surfaces as the implant has been incorporated into the living bone. ${ }^{18}$ Poor osseointegration of implants may be a risk factor for arthroplasty failure in the short and long term because of micromotion at the bone-implant interface, which can initiate periprosthetic bone resorption and subsequent loosening. ${ }^{19}$ This is particularly true in uncemented arthroplasty, which relies on implants integrating with surrounding bone. Optimal osseointegration requires formation of new bone at the bone-implant interface and there is evidence to suggest statins may promote bone growth and osteoblastogenesis via bone-morphogenetic protein-2 (BMP-2). Mundy et al. demonstrated an increase in $B M P-2$ expression, as detected by northern blot, in murine and human bone cells in response to simvastatin exposure, ${ }^{20}$ and that explanted neonatal murine calvaria demonstrated increased bone growth when exposed to simvastatin, fluvastatin, lovastatin and mevastatin. Furthermore, in vivo work demonstrated that lovastatin and simvastatin increased bone formation by nearly $50 \%$ in the calvaria of mice when injected subcutaneously, comparable to the effect seen with BMP-2 injection. ${ }^{20}$ In addition, statins have been shown to induce vascular endothelial growth factor (VEGF) expression. VEGF is a glycoprotein responsible for osteoblast differentiation and an angiogenic factor necessary for vascular invasion prior to bone formation, intercellular communication between endothelial cells and subsequent osteoblast activity necessary for bone growth. ${ }^{21}$

The potential for statins to promote osseointegration in vivo has been explored in multiple animal 
studies, with systemic administration of simvastatin after implant insertion demonstrating increased bone density around implants and crucially, an increase in the mechanical strength/stability of the bone-implant interface. ${ }^{22-25} \mathrm{Du}$ et al. demonstrated that administering oral simvastatin to osteoporotic rats (post oophorectomy) could increase implant-bone contact rate in cancellous bone when compared with untreated controls. ${ }^{24}$ $\mathrm{Li}$ et al. explored the effect of intraperitoneal simvastatin administration on peri-implant bone growth in rat tibial titanium implants and found an increase in bone formation in the treatment cohort when compared with controls. ${ }^{26}$

It has been proposed that local application of statins to implants may promote similar potential osteogenic effects, increasing mechanical strength and improving peri-implant bony calcification. ${ }^{27-29}$ Masuzaki et al. gave a single injection of fluvastatin-impregnated microspheres to rats with tibial titanium implants. This showed enhanced bone growth and bone contact as demonstrated by staining and microscopy around the implant and was accompanied by an increased bending strength. ${ }^{30}$ Similar studies have reported encouraging results with simvastatin-coated implants, scaffolds and biomaterials. ${ }^{31,32}$

Dose-dependency studies have suggested that implants coated with $75 \mu \mathrm{g}$ of fluvastatin osseointegrate better than control implants, for example a rodent model demonstrated improved implant trabecular bone layer composed of mineral bone and a thicker appearance of the new trabeculae in the medullary canal. Paradoxically at higher doses of fluvastatin $(300 \mu \mathrm{g})$ the implants perform worse, ${ }^{28}$ in that there is a delay in calcification of peri-implant bone. Moriyama et al. hypothesized that this is due to higher doses of fluvastatin yielding immature osteoblasts, normally developed by osteocalcin expression. ${ }^{28}$ The maturation of osteoblasts involves the fine balance of RUNX2 suppression (part of the BMP-2 signalling pathway) and Osterix enhancement, however statins have been thought to stimulate RUNX2 expression, potentially suppressing Osterix and the balance required for fully matured osteoblast formation, bone mineralisation and thereby osseointegration. ${ }^{28}$

Osseointegration generally occurs within 3 months of primary arthroplasty. ${ }^{33,34}$ Therefore preloading with statins prior to primary arthroplasty and early statin use in the initial weeks and months postimplant insertion could theoretically be associated with a reduction in complications as a result of suboptimal osseointegration, such as implant stem migration, periprosthetic fracture and loosening as a result of failure of trabecular bone ingrowth. ${ }^{35}$ This is supported by animal data from $\mathrm{Li}$ et al. who demonstrated that early use of statins after implant insertion promotes peri-implant bone growth, and discontinuation of statins in this early period leads to rebound bone resorption. ${ }^{26}$ Animal models should, however, be interpreted with caution. Many of the animal studies referenced administered statins for 30 days or less, osseointegration in humans is thought to occur within a more prolonged period (3 months). Furthermore, the dynamic forces on the human hip joint in gait are not directly comparable with those of animals used in the referenced studies. In addition, load bearing is an important aspect of lower limb arthroplasty osseointegration and some of the studies are not designed for load bearing of the implant.

\section{Statins and periprosthetic osteolysis}

Periprosthetic osteolysis (PPOL) is the gradual, progressive resorption of bone and subsequent reduction in bone density around the boneimplant interface in THA and TKA. ${ }^{36-38}$ The initial trigger for this process is activation of phagocytic cells in response to wear-related debris particles released from the bone-implant interface following arthroplasty. ${ }^{35,36}$ Specific articulation surface debris such as ultra-high molecular weight polyethylene (UHMWPE) have been implicated in phagocyte activation and the subsequent osteolytic cascade weakens the boneimplant interface. This process is generally asymptomatic and can go clinically undetected until there is decompensation and biomechanical instability. Symptomatic PPOL with aseptic loosening presents late and commonly revision arthroplasty is required to salvage joint function. Monocyte/macrophages and their derivatives have been implicated in the resorption of bone and PPOL in arthroplasty since early $1990 .{ }^{39}$

There is an established research base for a class of drug known as bisphosphonates (BP) in inhibiting osteoclast formation and function that is facilitated by their interaction with the mevalonate pathway by inhibition farnesyl pyrophosphate (FPP), downstream of the influence of statins. Some authors have highlighted the potential benefit of BP in arthroplasty survival in human ${ }^{40,41}$ and animal ${ }^{42,43}$ models. In a study using data 
from the Danish Hip Arthroplasty Register (DHAR), BP use for more than 240 days was associated with a reduction in the relative risk of revision of 0.58 (95\% CI; 0.32-1.05) for all indications. ${ }^{41}$ More recent research identified an associated risk reduction of up to $59 \%$ in those starting BP after arthroplasty surgery. ${ }^{40}$

Statins inhibit the mevalonate pathway upstream of FPP and have the potential to exert a similar molecular response as $\mathrm{BP}$, inhibiting the osteolytic cascade and reducing PPOL. A murine calvarial study noted that introduction of UHMWPE particles induced a pronounced bone resorption response when compared with controls; this effect was significantly abrogated in the group treated with simvastatin. ${ }^{44}$ Polymethylmethacrylate (PMMA) particles, released in cemented arthroplasty, have also been implicated as a potential trigger for PPOL via production of the pro-inflammatory cytokine tumour necrosis factor-alpha ( $\mathrm{TNF} \alpha$ ) by human monocytes. An in vitro experimental model of PMMA-induced inflammation using human peripheral blood monocytes has suggested that the potent HMG-CoA reductase inhibitor cerivastatin significantly inhibited this response via the intracellular Raf-MEK-ERK pathway. ${ }^{44}$ In a case-control study of patients with radiologically detectable femoral osteolysis in THA, the authors compared statin 'ever-users' and 'never-users' at 5 years post-THA. The relative risk ratio after adjustment for confounders (age, sex, activity level, body mass index, diagnosis, bearing surface, type of stem) was 0.38 (95\% CI 0.15, 0.99). This analysis did not have sufficient follow-up length to determine whether the risk of revision was lower in the statin ever-use group. ${ }^{45}$

Pro-inflammatory cytokines are considered to be major mediators of osteolysis and ultimately aseptic loosening; three of the most well characterized are interleukin-1 (IL-1), interleukin-6 (IL-6), and TNF $\alpha .{ }^{46}$ Experimentally it has been demonstrated that TNF $\alpha$ upregulates IL- 1 and IL- 6 and plays a pivotal role, both directly and indirectly, in the activation and recruitment of osteoclasts with subsequent induction of PPOL in total hip replacement. ${ }^{47} \mathrm{TNF} \alpha$ production is upregulated in experimental and clinical models of osteolysis, and this upregulation is further associated with particulate wear debris in vitro and in vivo. ${ }^{46,48,49}$ Similar molecular upregulation of both IL-1 $16,50,51$ and IL- $6^{46-52}$ has been reported in aseptic loosening models.
The presence of cells releasing IL-1, IL-6 and TNF has been directly correlated with the severity of osteolysis in THA and the authors suggest pharmacological modulation of these pathways may be a potential target for inhibition of prosthesis loosening. ${ }^{53}$ There is evidence to suggest that cerivastatin inhibits PMMA-induced inflammation in vitro via abrogation of TNF $\alpha .{ }^{54}$ Cerivastatin also reduces production of the chemokine monocyte chemotactic protein-1, which facilitates migration and infiltration of leukocytes into tissues. ${ }^{54,55}$ Simvastatin has been demonstrated experimentally to inhibit particle-mediated induction of IL-6 in human osteoblasts treated with titanium. ${ }^{56}$ Aseptic loosening and PPOL resulting from inflammatory processes occurring over a longer period of time may theoretically be reduced by long-term statin exposure. These data are summarized in Table 1 and a mechanistic model of statin effects is presented in Figure 1.

\section{Pharmacoepidemiological evidence of a role for statins in arthroplasty survival}

There is observational evidence which suggests that statins may impact on arthroplasty survival. Using data from the UK Clinical Practice Research Datalink (CPRD), Sarmanova et al. conducted a propensity score-matched cohort study, matching 178,467 statin users to the same number of nonstatin users to assess the impact of statins on risk of requiring joint arthroplasty for the treatment of $\mathrm{OA}$ and rheumatoid arthritis (RA). ${ }^{57}$ The results of the analysis suggested that statin prescriptions were associated with a reduced risk of joint arthroplasty due to RA but not OA.

Data from the DHAR identified 2349 patients who underwent THA between 1996 and 2005 and also had revision arthroplasty during this period. ${ }^{58}$ In a multivariable, propensity-score matched conditional logistic regression model, the relative risk $(95 \% \mathrm{CI})$ of revision in those exposed to statins compared with those unexposed was $0.34(0.28-0.41)$. Statin exposure was not modelled in a time-dependent manner but was more crudely assigned as 'ever versus never' statin exposure.

In a study which used data from both the CPRD in the UK and the Danish National Health System, Lalmohamed et al. analysed the association between statin exposure and revision of primary THA and TKA. ${ }^{59}$ In the primary analysis, 
Table 1. Summary of studies investigating links between statins and bone biology.

\begin{tabular}{|c|c|c|c|c|c|}
\hline Study & Model & Statin & $\begin{array}{l}\text { Mode of } \\
\text { administration }\end{array}$ & Observed effect & Conclusions \\
\hline Mundy et al. ${ }^{20}$ & $\begin{array}{l}\text { Cultured human (MG-63) } \\
\text { and murine (2T3) cell } \\
\text { lines with statin to assess } \\
\text { BMP-2 expression by } \\
\text { northern blot }\end{array}$ & Simvastatin & $\begin{array}{l}5 \mu \mathrm{M} \text { of statin } \\
\text { cultured with cell } \\
\text { lines for } 48 \mathrm{~h}\end{array}$ & $\begin{array}{l}\text { Increased BMP-2 } \\
\text { expression by northern } \\
\text { blot in cell lines exposed to } \\
\text { simvastatin for } 48 \mathrm{~h}\end{array}$ & $\begin{array}{l}\text { As BMP-2 increases } \\
\text { osteoblast differentiation } \\
\text { and proliferation, statins } \\
\text { may promote bone growth }\end{array}$ \\
\hline Mundy et al. ${ }^{20}$ & $\begin{array}{l}\text { Explanted neonatal } \\
\text { murine calvarial bones } \\
\text { were placed in tissue } \\
\text { culture medium with } \\
\text { test compound to assess } \\
\text { bone growth }\end{array}$ & $\begin{array}{l}\text { Simvastatin, } \\
\text { fluvastatin, } \\
\text { lovastatin } \\
\text { and } \\
\text { mevastatin }\end{array}$ & $\begin{array}{l}1 \mu \mathrm{M} \text { of test statin } \\
\text { was incubated with } \\
\text { the calvarial bone } \\
\text { for } 72 \mathrm{~h}\end{array}$ & $\begin{array}{l}\text { Increased bone growth on } \\
\text { histomorphometric analysis }\end{array}$ & $\begin{array}{l}\text { Simvastatin, fluvastatin, } \\
\text { lovastatin and mevastatin } \\
\text { all increased } \\
\text { bone formation by } \\
\text { approximately two- to } \\
\text { threefold, comparable } \\
\text { with BMP-2 and fibroblast } \\
\text { growth factor-1 }\end{array}$ \\
\hline Mundy et al. ${ }^{20}$ & $\begin{array}{l}\text { Statin injected into the } \\
\text { subcutaneous tissue } \\
\text { over the calvaria of mice } \\
\text { to assess growth in } \\
\text { calvarial bone }\end{array}$ & $\begin{array}{l}\text { Lovastatin } \\
\text { and } \\
\text { simvastatin }\end{array}$ & $\begin{array}{l}5 \mathrm{mg} / \mathrm{kg} / \text { day or } \\
10 \mathrm{mg} / \mathrm{kg} / \text { day of } \\
\text { statin injected } \\
\text { subcutaneously } \\
\text { over calvaria three } \\
\text { times a day for } \\
5 \text { days }\end{array}$ & $\begin{array}{l}\text { On histomorphometric } \\
\text { analysis at day } 21 \text {, a near } \\
50 \% \text { increase in bone } \\
\text { formation demonstrated } \\
\text { with statin administration }\end{array}$ & $\begin{array}{l}\text { Local subcutaneous } \\
\text { injection of statins may } \\
\text { increase bone formation }\end{array}$ \\
\hline Mundy et al. ${ }^{20}$ & $\begin{array}{l}\text { Statins administered } \\
\text { systemically to assess } \\
\text { effect on bone formation }\end{array}$ & Simvastatin & $\begin{array}{l}\text { Intraperitoneal } \\
\text { injection at } 14 \text { days } \\
\text { and } 4 \text { days prior to } \\
\text { sacrifice }\end{array}$ & $\begin{array}{l}\text { Tibia, femur and lumbar } \\
\text { vertebrae were analyzed by } \\
\text { histomorphometric analysis }\end{array}$ & $\begin{array}{l}\text { Simvastatin increased } \\
\text { trabecular bone } \\
\text { formation }\end{array}$ \\
\hline Du et al. ${ }^{24}$ & $\begin{array}{l}\text { Titanium implants } \\
\text { inserted into the tibia of } \\
\text { oophorectomized versus } \\
\text { sham surgery to assess } \\
\text { osseointegration in rats }\end{array}$ & Simvastatin & $\begin{array}{l}\text { Oral administration } \\
5 \mathrm{mg} / \mathrm{kg} \text { for either } \\
28 \text { days or } 84 \text { days } \\
\text { before sacrifice }\end{array}$ & $\begin{array}{l}\text { Increase in the percentage } \\
\text { of cancellous bone } \\
\text { to implant contact } \\
\text { as measured by } \\
\text { histomorphometric analysis } \\
\text { from both sides of the } \\
\text { implant; no significant } \\
\text { difference observed in } \\
\text { cortical bone contact }\end{array}$ & $\begin{array}{l}\text { Simvastatin may improve } \\
\text { osseointegration }\end{array}$ \\
\hline Li et al. ${ }^{26}$ & $\begin{array}{l}\text { Titanium tibial implant } \\
\text { inserted into mice and } \\
\text { bone growth assessed } \\
\text { by micro-CT scanning } \\
\text { and histomorphometric } \\
\text { analysis }\end{array}$ & Simvastatin & $\begin{array}{l}\text { Daily } \\
\text { intraperitoneal } \\
\text { injections of } 10 \mathrm{mg} / \\
\mathrm{kg} \text { of simvastatin } \\
\text { for } 7 \text { days }\end{array}$ & $\begin{array}{l}\text { Following } 7 \text { days of } \\
\text { simvastatin administration, } \\
\text { there was an increase in } \\
\text { peri-implant bone growth } \\
\text { compared with control. } \\
\text { There was a decrease in } \\
\text { bone growth following } \\
\text { simvastatin discontinuation } \\
\text { as confirmed by histology }\end{array}$ & $\begin{array}{l}\text { Short-term statin } \\
\text { administration is } \\
\text { associated with peri- } \\
\text { implant bone growth and } \\
\text { there is rebound loss of } \\
\text { bone on discontinuation }\end{array}$ \\
\hline Masuzaki et al. ${ }^{30}$ & $\begin{array}{l}\text { Single injection of } \\
\text { fluvastatin-impregnated } \\
\text { microspheres to rats } \\
\text { with tibial titanium } \\
\text { implants }\end{array}$ & Fluvastatin & $\begin{array}{l}\text { Fluvastatin- } \\
\text { impregnated } \\
\text { microspheres } \\
\text { were injected } \\
\text { beneath the skin } \\
\text { at the implant site } \\
\text { following surgery }\end{array}$ & $\begin{array}{l}\text { Peri-implant bone growth } \\
\text { measured by staining } \\
\text { and light microscopy } \\
\text { demonstrated an increase } \\
\text { in bone growth and bone } \\
\text { strength was increased } \\
\text { when assessed by three- } \\
\text { point bending }\end{array}$ & $\begin{array}{l}\text { A single injection of } \\
\text { fluvastatin-impregnated } \\
\text { microspheres increased } \\
\text { implant osseointegration } \\
\text { and the mechanical } \\
\text { strength of the bone }\end{array}$ \\
\hline Laing et al. ${ }^{54}$ & $\begin{array}{l}\text { In vitro model of } \\
\text { monocyte/macrophage } \\
\text { inflammatory response } \\
\text { to PMMA particles, } \\
\text { compared with } \\
\text { pretreatment with statin }\end{array}$ & Cerivastatin & $\begin{array}{l}\text { Cerivastatin } \\
\text { dissolved in media } \\
\text { to } 150 \mu \mathrm{M} \text { or } 300 \mu \mathrm{M} \\
\text { for } 1 \mathrm{~h} \text { followed by } \\
\text { PMMA exposure } \\
\text { for } 23 \mathrm{~h}\end{array}$ & $\begin{array}{l}\text { Inflammatory cytokine } \\
\text { TNF } \alpha \text { production is } \\
\text { significantly abrogated with } \\
\text { cerivastatin pretreatment }\end{array}$ & $\begin{array}{l}\text { Cerivastatin reduces } \\
\text { production of a pro- } \\
\text { inflammatory cytokine } \\
\text { implicated in osteolysis }\end{array}$ \\
\hline
\end{tabular}

BMP-2, bone-morphogenetic protein-2; CT, computed tomography; PMMA, polymethylmethacrylate; TNF $\alpha$, tumour necrosis factor-alpha. 


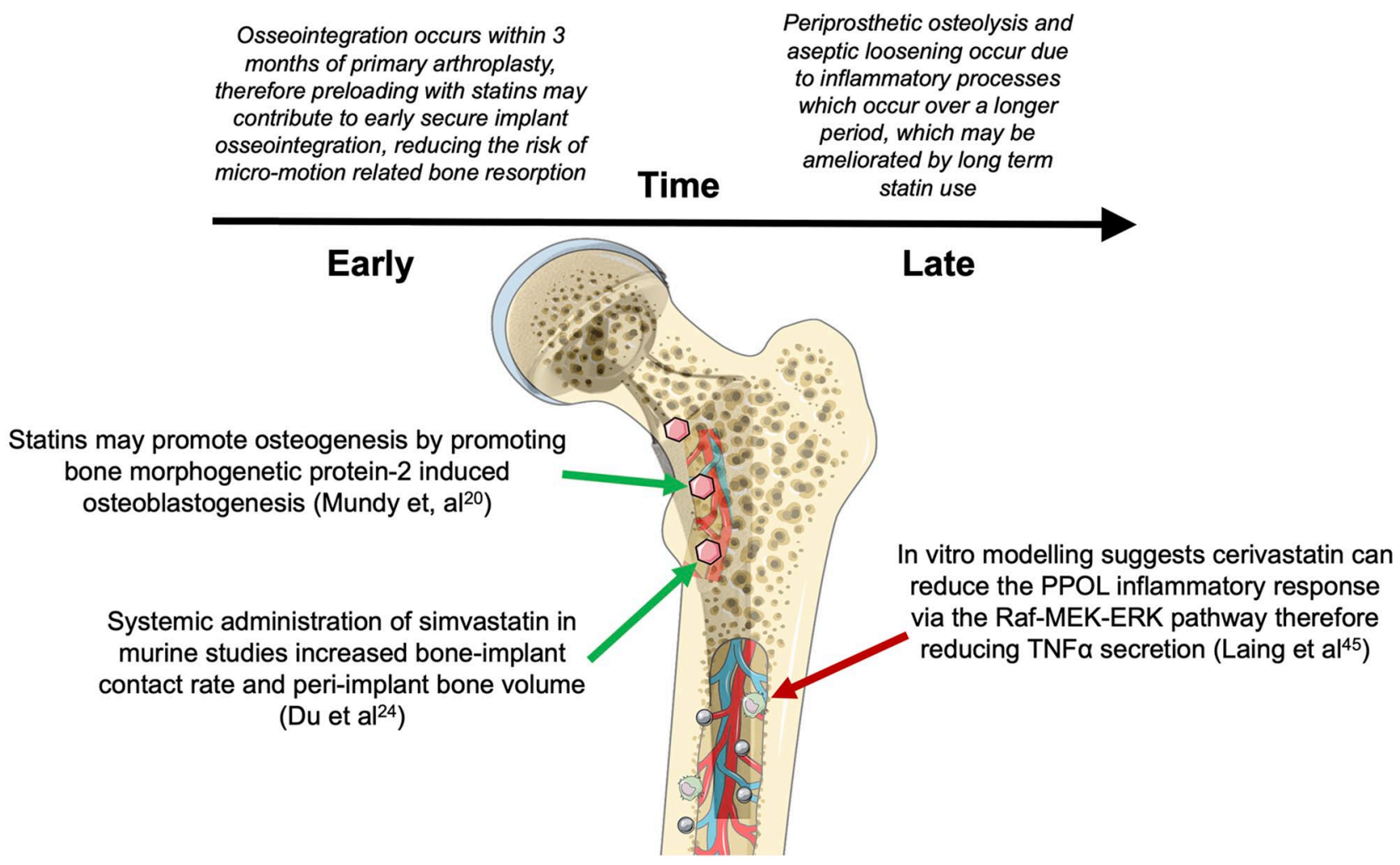

Figure 1. Mechanistic model of interaction between statins and bone-implant interface biology.

PPOL, periprosthetic osteolysis; TNF $\alpha$, tumour necrosis factor-alpha.

statin exposure was modelled in a time-dependent manner from the date of the primary THA/ TKA. Using data from both cohorts, statin exposure was associated with a small though significant reduction in risk of revision (incident rate ratio $=0.9 ; 95 \% \mathrm{CI}, 0.89,0.96)$. A more recent analysis using CPRD data looked at impact of duration and timing of statin exposure on revision risk. ${ }^{60}$ Of those exposed to statins following THA/TKA, 852 (1.3\%) had revision arthroplasty, compared with 2648 (3.1\%) of those unexposed, with an adjusted hazard ratio for revision in those exposed versus those unexposed of $0.82(0.75,0.90)$. Similar results were seen in participants who had a THA $0.86(0.76,0.98)$ and TKA $0.76(0.66,0.88)$. Exposure in the first 5 years following surgery appeared protective: compared with those who were not exposed to statins, the hazard ratio of revision in those first exposed to statins in the periods $0-1$ years and $1-5$ years after the primary surgery was 0.82 $(0.74,0.91)$ and $0.76(0.65,0.90)$, respectively. No statistically significant effect of statin exposure on revision risk $>5$ years following primary surgery was observed. Compared with participants exposed to statins for a total duration of less than 1 year, exposure for $1-2,2-3,3-4$ and 4-5 years did not appear to be associated with THA/TKA revision risk, though exposure for a total duration of $>5$ years was associated with a reduced hazard ratio of $0.74(0.62,0.88)$ for revision surgery. ${ }^{60}$ The data from these studies demonstrate a small but significant effect of statins on reducing the risk of revision arthroplasty. There are however important limitations in interpreting the data and in particular the potential for unmeasured confounding factors which may have influenced the observed associations, and also changes in surgical technique and implants which have occurred during the course of the observation period. The findings are less convincing than those observed in animal/in vitro studies, highlighting the importance of human studies in investigating the association.

\section{Conclusion}

There is some evidence from animal and in vitro models to suggest that statin therapy may promote osseointegration and reduce PPOL. Data from observational clinical studies support a weak effect of statins on arthroplasty revision. 
However there are significant limitations to the interpretation of these data, such as the potential for unmeasured confounding factors to influence results and improvements in surgical technique and implants during the study period.

Taken together the published literature suggests that although there is likely an association between statin therapy and reduced revision risk in lower limb arthroplasty and a body of mechanistic evidence from animal models, the causal relationship is far from clear and there is currently inadequate evidence to recommend routine clinical prescribing of statin therapy in patients undergoing arthroplasty of the hip or knee.

\section{Conflict of interest statement}

The authors declare that there is no conflict of interest.

\section{Funding}

The authors disclosed receipt of the following financial support for the research, authorship, and/or publication of this article: This research was supported by the NIHR Manchester Biomedical Research Centre. Antony K. Sorial and Sami A. Anjum were funded through the NIHR integrated academic training programme. Funding for Michael J. Cook was provided by the John Charnley Trust and Wrightington Three Wishes Foundation.

\section{ORCID iD}

Antony K. Sorial (D) https://orcid.org/0000-0002 $-4449-014 \mathrm{X}$

\section{References}

1. O'Neill TW, McCabe PS and McBeth J. Update on the epidemiology, risk factors and disease outcomes of osteoarthritis. Best Pract Res Clin Rheumatol 2018; 32: 312-326.

2. Murray CJ, Richards MA, Newton JN, et al. UK health performance: findings of the global burden of disease study 2010. Lancet 2013; 381: 997-1020.

3. Chen A, Gupte C, Akhtar K, et al. The global economic cost of osteoarthritis: how the UK compares. Arthritis 2012; 2012: 698709.

4. Tsertsvadze A, Grove A, Freeman K, et al. Total hip replacement for the treatment of end stage arthritis of the hip: a systematic review and metaanalysis. PLoS One 2014; 9: e99804.
5. National Joint Registry. National foint Registry for England, Wales and Northern Ireland, 15th annual report. NJR, 2018.

6. National Joint Registry. National foint Registry for England, Wales and Northern Ireland, 7th annual report. NJR, 2010.

7. Ong KL, Lau E, Suggs J, et al. Risk of subsequent revision after primary and revision total joint arthroplasty. Clin Orthop Relat Res 2010; 468: 3070-3076.

8. Patil S, Garbuz DS, Greidanus NV, et al. Quality of life outcomes in revision vs primary total hip arthroplasty: a prospective cohort study. $\mathcal{F}$ Arthroplasty 2008; 23: 550-553.

9. Bozic KJ, Katz P, Cisternas M, et al. Hospital resource utilization for primary and revision total hip arthroplasty. F Bone foint Surg Am 2005; 87: 570-576.

10. Lavernia CJ, Drakeford MK, Tsao AK, et al. Revision and primary hip and knee arthroplasty. A cost analysis. Clin Orthop Relat Res 1995; 311: 136-141.

11. Crowe JF, Sculco TP and Kahn B. Revision total hip arthroplasty: hospital cost and reimbursement analysis. Clin Orthop Relat Res 2003: $175-182$.

12. Stancu $C$ and Sima A. Statins: mechanism of action and effects. $\mathcal{F}$ Cell Mol Med 2001; 5: 378-387.

13. Sacks FM, Pfeffer MA, Moye LA, et al. The effect of pravastatin on coronary events after myocardial infarction in patients with average cholesterol levels. Cholesterol and recurrent events trial investigators. $N$ Engl f Med 1996; 335: 1001-1009.

14. Pedersen TR, Kjekshus J, Berg K, et al. Randomised trial of cholesterol lowering in 4444 patients with coronary heart disease: the Scandinavian Simvastatin survival study (4S). 1994. Atheroscler Suppl 2004; 5: 81-87.

15. Scarborough $\mathrm{P}$, Wickramasinghe $\mathrm{K}$, Bhatnagar $\mathrm{P}$, et al. Trends in coronary heart disease 1961-2011. London: The British Heart Foundation, 2011.

16. Mo H, Yeganehjoo H, Shah A, et al. Mevalonatesuppressive dietary isoprenoids for bone health. $\mathcal{F}$ Nutr Biochem 2012; 23: 1543-1551.

17. Albrektsson $\mathrm{T}$ and Johansson C. Osteoinduction, osteoconduction and osseointegration. Eur Spine f 2001; 10(Suppl. 2): S96-S101.

18. Mavrogenis AF, Dimitriou R, Parvizi J, et al. Biology of implant osseointegration. $\mathcal{F}$ Musculoskelet Neuronal Interact 2009; 9: 61-71. 
19. Jakobsen T, Kold S, Baas J, et al. Sheep hip arthroplasty model of failed implant osseointegration. Open Orthop f 2015; 9: 525-529.

20. Mundy G, Garrett R, Harris S, et al. Stimulation of bone formation in vitro and in rodents by statins. Science 1999; 286: 1946-1949.

21. Maeda T, Kawane T and Horiuchi N. Statins augment vascular endothelial growth factor expression in osteoblastic cells via inhibition of protein prenylation. Endocrinology 2003; 144: 681-692.

22. Ayukawa Y, Okamura A and Koyano K. Simvastatin promotes osteogenesis around titanium implants. Clin Oral Implants Res 2004; 15: 346-350.

23. Basarir K, Erdemli B, Can A, et al. Osseointegration in arthroplasty: can simvastatin promote bone response to implants? Int Orthop 2009; 33: 855-859.

24. Du Z, Chen J, Yan F, et al. Effects of simvastatin on bone healing around titanium implants in osteoporotic rats. Clin Oral Implants Res 2009; 20: 145-150.

25. Yin H, Li J, Yu X, et al. Effects of simvastatin on osseointegration in a canine total hip arthroplasty model: an experimental study. $\mathcal{F}$ Arthroplasty 2011; 26: 1534-1539.

26. Li X, Wu F, Zhang Y, et al. Discontinuation of simvastatin leads to a rebound phenomenon and results in immediate peri-implant bone loss. Clin Exp Dent Res 2016; 2: 65-72.

27. Moriyama Y, Ayukawa Y, Ogino Y, et al. Topical application of statin affects bone healing around implants. Clin Oral Implants Res 2008; 19: 600-605.

28. Moriyama Y, Ayukawa Y, Ogino Y, et al. Local application of fluvastatin improves peri-implant bone quantity and mechanical properties: a rodent study. Acta Biomater 2010; 6: 1610-1618.

29. Ayukawa Y, Yasukawa E, Moriyama Y, et al. Local application of statin promotes bone repair through the suppression of osteoclasts and the enhancement of osteoblasts at bone-healing sites in rats. Oral Surg Oral Med Oral Pathol Oral Radiol Endod 2009; 107: 336-342.

30. Masuzaki T, Ayukawa Y, Moriyama Y, et al. The effect of a single remote injection of statinimpregnated poly (lactic-co-glycolic acid) microspheres on osteogenesis around titanium implants in rat tibia. Biomaterials 2010; 31: 3327-3334.

31. Montero J, Manzano G and Albaladejo A. The role of topical simvastatin on bone regeneration: a systematic review. $\mathcal{F}$ Clin Exp Dent 2014; 6: e286-e290.

32. Pauly S, Back DA, Kaeppler K, et al. Influence of statins locally applied from orthopedic implants on osseous integration. BMC Musculoskelet Disord 2012; 13: 208.

33. Klein CP, Patka P, Wolke JG, et al. Long-term in vivo study of plasma-sprayed coatings on titanium alloys of tetracalcium phosphate, hydroxyapatite and alpha-tricalcium phosphate. Biomaterials 1994; 15: 146-150.

34. Hardy DC, Frayssinet P, Krallis P, et al. Histopathology of a well-functioning hydroxyapatite-coated femoral prosthesis after 52 months. Acta Orthop Belg 1999; 65: 72-82.

35. Goodman SB, Yao Z, Keeney M, et al. The future of biologic coatings for orthopaedic implants. Biomaterials 2013; 34: 3174-3183.

36. Gallo J, Goodman SB, Konttinen YT, et al. Particle disease: biologic mechanisms of periprosthetic osteolysis in total hip arthroplasty. Innate Immun 2013; 19: 213-224.

37. Sabokbar A, Itonaga I, Sun SG, et al. Arthroplasty membrane-derived fibroblasts directly induce osteoclast formation and osteolysis in aseptic loosening. F Orthop Res 2005; 23: 511-519.

38. Purdue PE, Koulouvaris P, Potter HG, et al. The cellular and molecular biology of periprosthetic osteolysis. Clin Orthop Relat Res 2007; 454: 251-261.

39. Athanasou NA, Quinn J and Bulstrode CJ. Resorption of bone by inflammatory cells derived from the joint capsule of hip arthroplasties. $\mathcal{F}$ Bone foint Surg Br 1992; 74: 57-62.

40. Prieto-Alhambra D, Javaid MK, Judge A, et al. Association between bisphosphonate use and implant survival after primary total arthroplasty of the knee or hip: population based retrospective cohort study. BMF 2011; 343: d7222.

41. Thillemann TM, Pedersen AB, Mehnert F, et al. Postoperative use of bisphosphonates and risk of revision after primary total hip arthroplasty: a nationwide population-based study. Bone 2010; 46: 946-951.

42. Venesmaa PK, Kroger HP, Miettinen HJ, et al. Alendronate reduces periprosthetic bone loss after uncemented primary total hip arthroplasty: a prospective randomized study. $\mathcal{F}$ Bone Miner Res 2001; 16: 2126-2131.

43. Wang CJ, Wang JW, Weng LH, et al. The effect of alendronate on bone mineral density in the distal part of the femur and proximal part of the 
tibia after total knee arthroplasty. $\mathcal{F}$ Bone foint Surg Am 2003; 85: 2121-2126.

44. von Knoch F, Heckelei A, Wedemeyer C, et al. The effect of simvastatin on polyethylene particle-induced osteolysis. Biomaterials 2005; 26: 3549-3555.

45. Lubbeke A, Garavaglia G, Rothman KJ, et al. Statins may reduce femoral osteolysis in patients with total hip arthroplasty. F Orthop Res 2013; 31: 814-820.

46. Goodman SB, Huie P, Song Y, et al. Cellular profile and cytokine production at prosthetic interfaces. Study of tissues retrieved from revised hip and knee replacements. F Bone foint Surg Br 1998; 80: 531-539.

47. Xu JW, Konttinen YT, Lassus J, et al. Tumor necrosis factor-alpha (TNF-alpha) in loosening of total hip replacement (THR). Clin Exp Rheumatol 1996; 14: 643-648.

48. Kobayashi Y, Kim KJ and Itoh T. Gene expression of bone-resorbing cytokines in rat osteolysis model. F Orthop Sci 2005; 10: 62-69.

49. Taki N, Tatro JM, Nalepka JL, et al. Polyethylene and titanium particles induce osteolysis by similar, lymphocyte-independent, mechanisms. f Orthop Res 2005; 23: 376-383.

50. Jiranek WA, Machado M, Jasty M, et al. Production of cytokines around loosened cemented acetabular components. Analysis with immunohistochemical techniques and in situ hybridization. F Bone foint Surg Am 1993; 75: 863-879.

51. Konttinen YT, Kurvinen H, Takagi M, et al. Interleukin-1 and collagenases around loosening total hip prostheses. Clin Exp Rheumatol 1996; 14: 255-262.

52. Konttinen YT, Xu JW, Waris E, et al. Interleukin- 6 in aseptic loosening of total hip replacement prostheses. Clin Exp Rheumatol 2002; 20: 485-490.

53. Stea S, Visentin M, Granchi D, et al. Cytokines and osteolysis around total hip prostheses. Cytokine 2000; 12: 1575-1579.

54. Laing AJ, Dillon JP, Mulhall KJ, et al. Statins attenuate polymethylmethacrylate-mediated monocyte activation. Acta Orthop 2008; 79: 134-140.

55. Deshmane SL, Kremlev S, Amini S, et al. Monocyte chemoattractant protein-1 (MCP-1): an overview. F Interferon Cytokine Res 2009; 29: 313-326.

56. Valles G, Perez C, Bore A, et al. Simvastatin prevents the induction of interleukin- 6 gene expression by titanium particles in human osteoblastic cells. Acta Biomater 2013; 9: 4916-4925.

57. Sarmanova A, Doherty M, Kuo C, et al. Statin use and risk of joint replacement due to osteoarthritis and rheumatoid arthritis: a propensity-score matched longitudinal cohort study. Rheumatology (Oxford) 2020; 59: 2898-2907.

58. Thillemann TM, Pedersen AB, Mehnert F, et al. The risk of revision after primary total hip arthroplasty among statin users: a nationwide population-based nested case-control study. f Bone Foint Surg Am 2010; 92: 1063-1072.

59. Lalmohamed A, van Staa TP, Vestergaard P, et al. Statins and risk of lower limb revision surgery: the influence of differences in study design using electronic health records from the United Kingdom and Denmark. Am $\mathcal{F}$ Epidemiol 2016; 184: 58-66.

60. Cook MJ, Sorial AK, Lunt M, et al. Effect of timing and duration of statin exposure on risk of hip or knee revision arthroplasty: a population-based cohort study. F Rheumatol. Epub ahead of print 15 March 2019. DOI: 10.3899/jrheum.180574.
Visit SAGE journals online journals.sagepub.com/ home/tab

(SAGE journals 